\title{
ERH overexpression is associated with decreased cell migration and invasion and a good prognosis in gastric cancer
}

\author{
Ji-Ho Park ${ }^{1 \#}$, Miyeong Park ${ }^{2 \#}$, Sun Yi Park ${ }^{1}$, Young-Joon Lee ${ }^{1}$, Soon-Chan Hong', Eun-Jung Jung ${ }^{1}$, \\ Young-Tae Ju ${ }^{1}$, Chi-Young Jeong ${ }^{1}$, Ju-Yeon Kim ${ }^{1}$, Gyung Hyuck Ko ${ }^{3}$, Young-Sool Hah ${ }^{4}$, Sang-Ho Jeong ${ }^{1 \wedge}$ \\ ${ }^{1}$ Department of Surgery, Gyeongsang National University School of Medicine and Gyeongsang National University Hospital, Jinju, Korea; \\ ${ }^{2}$ Department of Anesthesiology, Gyeongsang National University Changwon Hospital, Changwon, Korea; ${ }^{3}$ Department of Pathology, School of \\ Medicine, Gyeongsang National University, Jinju, Korea; ${ }^{4}$ Biomedical Research Institute, Gyeongsang National University Hospital, Jinju, Korea \\ Contributions: (I) Conception and design: JH Park, SH Jeong; (II) Administrative support: MY Park, SY Park; (III) Provision of study materials or \\ patients: YJ Lee, SC Hong, EJ Jung; (IV) Collection and assembly of data: YT Ju, CY Jeong, JY Kim; (V) Data analysis and interpretation: GH Ko, \\ YS Hah, SH Jeong; (VI) Manuscript writing: All authors; (VII) Final approval of manuscript: All authors. \\ \#These authors contributed equally to this work. \\ Correspondence to: Sang-Ho Jeong, MD, PhD. Associate Professor, Department of Surgery, Gyeongsang National University School of Medicine and \\ Gyeongsang National University Hospital, 11 Samjungja-ro, Sungsan-gu, Changwon-si, Gyeongsangnam-do 51472, Korea. Email: shjeong@gnu.ac.kr.
}

Background: The enhancer of rudimentary homolog (ERH) protein is implicated in transcriptional regulation, cell cycle progression, and malignancy. We previously conducted a proteomics analysis using gastric cancer (GC) tissues and identified ERH as a biomarker candidate. The aim of this study was to investigate whether ERH may be useful as a prognostic marker for GC.

Methods: Surgically resected GC tissue specimens were obtained from 327 patients who underwent gastrectomy at Gyeongsang National University Hospital. Immunohistochemistry (IHC) was used to validate ERH as a prognostic marker in these tissues. SNU601 and MKN74 cells with siRNA-mediated knockdown of ERH expression and ERH-overexpressing SNU601 and MKN74 knock-in cells were used for analysis of ERH function.

Results: ERH was overexpressed in stomach cancer tissues compared with normal tissues according to proteomics analysis $(n=29, P<0.01)$ of patient samples. Based on IHC, patients with tumors overexpressing ERH had lower T stage and lower TNM stage classifications, lower cancer recurrence rates and longer survival times than did patients with tumors showing low expression of ERH $(\mathrm{P}=0.04)$. In vitro, forced expression of ERH significantly decreased GC cell migration and invasion, and depletion of ERH triggered GC cell migration and invasion but had no effect on proliferation in vitro.

Conclusions: The findings from the present study show that ERH is associated with decreased cancer cell migration and invasion, suggesting that overexpression of ERH may serve as a marker of good prognosis for patients with GC.

Keywords: Stomach neoplasm; enhancer of rudimentary homolog (ERH); immunohistochemistry (IHC); biomarker

Submitted Mar 13, 2020. Accepted for publication Jul 08, 2020.

doi: $10.21037 /$ tcr-20-1498

View this article at: http://dx.doi.org/10.21037/tcr-20-1498

^ ORCID: 0000-0001-9061-6236. 


\section{Introduction}

Gastric cancer (GC) is the fourth most common malignancy and the third leading cause of cancer death worldwide (1). Surgery and adjuvant chemotherapy are the mainstays of curative treatment. Although advances have been made in these strategies, the 5 -year survival rate of stage III stomach cancer is reported to be approximately $50 \%(2,3)$. For patients with metastatic GC, a combination of traditional cytotoxic chemotherapy regimens result in a median survival of 9-11 months. As intensive chemotherapy is associated with increased survival but also enhanced toxicity in patients with performance status often compromised by malignancy, treatments with increased efficacy and decreased toxicity are needed. For this reason, targeted therapy for treating GC has attracted increasing interest. Despite advances in the understanding of GC at the molecular level and the emergence of targeted therapy, predictive biomarkers for this disease are lacking (4).

Targeted therapy was started after the ToGA trial of trastuzumab [a monoclonal antibody against human epidermal growth factor receptor 2 (HER2)] was undertaken for GC (5). Recently, pembrolizumab was added as a second-line therapy for patients with inoperable GC (6). We previously conducted a proteomics analysis of 152 human GC clinical specimens to identify candidate target proteins differentially expressed in gastric tumor tissues and compared their levels to those in healthy tissues. Of the 430 proteins, enhancer of rudimentary homolog (ERH) was identified (7). ERH is ubiquitously expressed in both adult and fetal tissues and localizes predominantly in the nucleus (8). ERH is reported to have several binding proteins, some of which are involved in transcriptional regulation, cell growth, or cell cycle progression (8-11). Based on these reports, ERH may be involved in various cellular functions. Several reports have examined ERH expression in malignancy, and ERH expression was found to be clearly upregulated in malignant breast cancer cells compared to benign breast cells in both primary human breast cancer and in cell models of breast cancer. As these results were similar to the results obtained for ovarian cancer, ERH overexpression (ERH-OE) may be generally involved in the initiation and/or progression of certain human malignancies (12).

However, few studies have reported an association of ERH with GC. The aim of this study was to investigate whether ERH may be used as a prognostic marker for GC.
We present the following article in accordance with the REMARK reporting checklist (available at http://dx.doi. org/10.21037/tcr-20-1498).

\section{Methods}

\section{Stomach tissue samples for tissue microarray (TMA)}

We collected GC tissue specimens from 319 patients who underwent gastrectomy at Gyeongsang National University Hospital between January 1, 2004, and December 31, 2007. We retrospectively collected the medical information and clinicopathologic data for the patients by a review of the electric medical chart and pathologic reports. We assessed mortality via examination of the medical chart after a recent visit, and we called patients who had not visited the hospital for 6 months. We censored patients who did not visit for more than 6 months and did not receive the telephone call. For survival analysis, we consulted the National Statistical Office of the Republic of Korea.

The study was conducted in accordance with the Declaration of Helsinki (as revised in 2013). The study was approved by the Institutional Review Board of Gyeongsang National University Hospital (GNUHIRB 2009-54) and informed consent was taken from all the patients.

\section{TMA analysis \& immunohistochemistry (IHC)}

We obtained core tissue biopsy samples (2 $\mathrm{mm}$ diameter) from tumor paraffin blocks (donor blocks). These specimens were inserted into new paraffin blocks, and IHC staining was performed on 4- $\mu$ m-thick sections. Briefly, the tissue sections were deparaffinized and rehydrated, and the slides were incubated for 60 minutes at room temperature with a specific antibody against ERH (rabbit polyclonal antibody, 1:25; Atlas Antibodies AB, Stockholm, Sweden). We used an UltraVision LP detection system (Lab Vision Corporation, Fremont, CA, USA) to detect expression. The scoring of ERH expression was performed by a pathologist (K. H. Ko) who was blinded to the clinicopathological data. The extent of the histochemical reaction in the nucleus was scored according to the percentage of ERH-positive cells as follows: 2+ (25-49\%) and 3+ (50-74\%) (Figure 1) (13).

\section{Statistical analysis}

All statistical analyses were performed using SPSS Statistics 

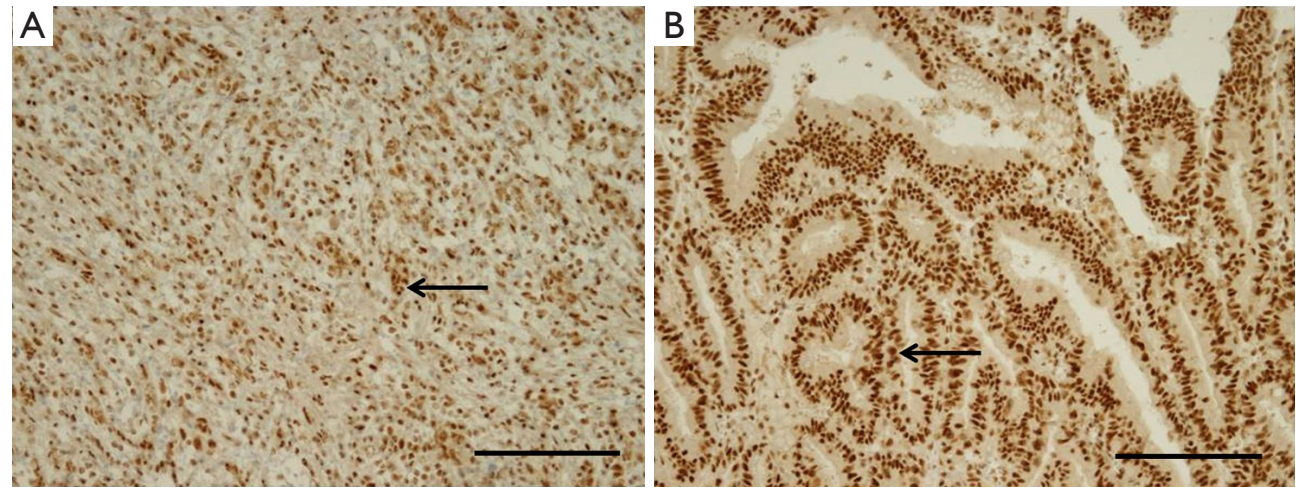

Figure 1 Results from immunohistochemical analysis of ERH expression in GC tissues. Staining with an anti-ERH antibody was scored and sorted into groups according to the percentage of ERH-positive cells as follows: (A) 2+ reactivity (25-49\%), and (B) 3+ reactivity (50-74\%). Arrows show representative cells with positive staining for ERH. Scale bar, $100 \mu \mathrm{m}$. ERH, enhancer of rudimentary homolog; GC, gastric cancer.

version 24 (IBM SPSS, Inc., Chicago, IL, USA). Data represent the mean $\pm \mathrm{SD}$. The statistical analyses of the mean values were performed via $t$-tests, and statistical analyses of frequency were performed with $\chi^{2}$ tests. The Kaplan-Meier method was applied for survival analysis. In all analyses, $\mathrm{P}$ values less than 0.05 were considered statistically significant.

\section{Cell culture}

The human stomach adenocarcinoma cell lines MKN74 and SNU601 were purchased from Korea Cell Line Bank. The cells were cultured in RPMI 1640 (Gibco, Thermo Fisher Scientific, Inc., Waltham, MA, USA) medium with $10 \%$ heat inactivated FBS (Gibco, Thermo Fisher Scientific, Inc.) and penicillin $(100 \mathrm{U} / \mathrm{mL}$, Thermo Fisher Scientific, Inc.) in a $5 \% \mathrm{CO}_{2}$ atmosphere at $37^{\circ} \mathrm{C}$.

\section{Western blot analysis}

Cells were suspended in lysis (RIPA) buffer containing $1 \%$ protease inhibitor cocktail (Sigma, St. Louis, MO, USA), and lysates were centrifuged at 13,000 rpm for 15 minutes at $4{ }^{\circ} \mathrm{C}$. The protein concentrations were quantified using a Bio-Rad protein assay kit (Bio-Rad, CA, USA). Then, a $30-\mu \mathrm{g}$ sample of the extracted proteins was subjected to $15 \%$ SDS-polyacrylamide gel electrophoresis and transferred onto PVDF membranes (iBlot 2PVDF Regular Stacks, Invitrogen, Thermo Fisher Scientific, Inc.). The membranes were blocked with $5 \%$ nonfat dry milk in TBST solution $[10 \mathrm{mM}$ Tris- $\mathrm{HCl}(\mathrm{pH} 8.0)$,
$150 \mathrm{mM} \mathrm{NaCl}$, and $0.05 \%$ Tween 20] for $1 \mathrm{~h}$ at room temperature. The protein blots were incubated with primary antibodies (ERH 1:1,000, Sigma, St. Louis, MO, USA) overnight at $4{ }^{\circ} \mathrm{C}$. Detection was performed using enhanced chemiluminescence reagents (ECL, Thermo, Rockford, IL, USA). An anti- $\beta$-actin (1:1,000, Santa Cruz Biotech, Dallas, TX, USA) antibody was used to normalize the quantity of the loaded samples.

\section{$R N A$ interference experiments}

Two different siRNA oligonucleotide duplexes targeting ERH genes (designated siERH-3 and siERH-4) were purchased from Dharmacon. The sequences were 5'-UCAGUCAGUUFUUUFAUUU-3' (siERH-3) and 5 '-GAACUUAUGCUGACUACGA-3' (siERH-4). Transient transfection of each siRNA duplex was performed using the Lipofectamine ${ }^{\mathrm{TM}} 3000$ (Invitrogen; Thermo Fisher Scientific, Inc.) transfection reagent according to the manufacturer's instructions.

\section{Construction and transfection of ERH-expressing plasmids}

Human ERH cDNA was purchased from OriGene (RC200367). Cells were transfected with ERH-expressing plasmids using Lipofectamine ${ }^{\mathrm{TM}} 3000$ (Invitrogen; Thermo Fisher Scientific, Inc.) in accordance with the manufacturer's instructions. After $48 \mathrm{~h}$, the cells were treated with neomycin for selection. ERH expression in neomycinresistant clones was examined by immunoblotting. The pCMV6 empty vector was used as a control. 


\section{Proliferation assay}

Cell viability was assayed using a 3-(4,5-dimethylthiazol2-yl)-2,5-diphenyltetrazolium bromide (MTT) assay (Sigma). Briefly, MKN74 and SNU601 cells were seeded onto 24 -well plates at $2 \times 10^{4}$ cells/well. These plates were then incubated in a humidified incubator with $5 \% \mathrm{CO}_{2}$ at $37^{\circ} \mathrm{C}$. After incubation for $24,48,72$ or $96 \mathrm{~h}$, the MTT assay was performed by adding $200 \mu \mathrm{L}$ of MTT solution $(0.5 \mathrm{mg} / \mathrm{mL})$ for $3 \mathrm{~h}$ to convert the MTT to formazan. The supernatant was removed, and $500 \mu \mathrm{L}$ of DMSO was added to each well. The optical density (OD) of the solution at $570 \mathrm{~nm}$ was measured using a VersaMax ELISA microplate reader (Molecular Devices, US/ Versamax). Each experiment was repeated three times independently.

\section{Invasion and migration assays}

The invasive ability of cancer cells was assessed using a Matrigel-based Transwell system. Briefly, the upper chambers of the Transwell system were coated with Matrigel (BD Bioscience \#356234, San Jose, CA, USA) and incubated at $37{ }^{\circ} \mathrm{C}$ for $4 \mathrm{~h}$ or overnight. MKN74 and SNU601 cells were adjusted to $1 \times 10^{5}$ and seeded in medium without FBS onto the upper chamber of the Transwell. Following incubation for 48 or $72 \mathrm{~h}$ in a $5 \%$ atmosphere $\mathrm{CO}_{2}$ incubator at $37^{\circ} \mathrm{C}$, the cells on the top surface of the membrane were removed by wiping with a cotton swab, and the cells on the underside were fixed in $4 \%$ formaldehyde fixing solution (with $0.1 \%$ Triton X-100 in PBS) and stained with 4,6-diamidino-2-phenylindole (DAPI) solution. Quantification was performed by counting five randomly selected $10 \times$ magnification fields. Values for cell invasion are expressed as the mean number of cells per microscopic field over five fields per filter for triplicate experiments. The experiments were performed in triplicate at least three times independently. For woundhealing assays, MKN74 cells and snu601 cells $\left(1.4 \times 10^{5}\right.$ per well in $70 \mu \mathrm{L}$ of medium) were seeded in culture insert 2-wells (ibidi, Martinsried, Germany) in 6-well plates. After removal of the insert well, the cells were incubated in fresh medium. Photomicrographs of the migration assay were taken at 0,24 , and $48 \mathrm{~h}$ with a microscope. Cell migration was quantified using NIH ImageJ software. Data are presented as the mean $\pm \mathrm{SD}$ for triplicate independent experiments.

\section{Results}

Patients with TMA sample ERH-OE had decreased tumor invasion, TNM stage classification, and cancer recurrence rates

Immunohistochemical staining was performed to analyze ERH expression in 319 GC tissue samples as TMA blocks. The subjects comprised 208 male and 111 female patients with an average age of $62.1 \pm 11.1$ years. The mean tumor size was $4.2 \pm 2.6 \mathrm{~cm}$, and the mean number of lymph nodes (LNs) metastasized was 2.2. The tumor TNM stage classifications were as follows: stage I, 60.2\% ( $\mathrm{n}=192)$; stage II, $17.9 \%(\mathrm{n}=57)$; and stage III, $21.9 \%(\mathrm{n}=70)$. The mean follow-up period was 55.5 months, and GC recurred in $18.5 \%(\mathrm{n}=59)$ of the patients.

The staining intensity used to determine the level of ERH expression in the cytoplasm of cancer cells differed for each tissue. Of the $319 \mathrm{GC}$ tissue samples, $11.9 \%$ of the samples [38] scored 2+, and 88.1\% [281] scored 3+. Samples with scores of $2+$ and $3+$ were considered to have were considered to have ERH protein underexpression (ERHUE) and overexpression, respectively (Figure 1).

The results of the immunohistochemical analysis were compared between the patients with ERH-OE (score 3+) and ERH-UE (score 2+). There was no difference between the two groups in terms of WHO classification, LN metastasis, or cancer-related death $(\mathrm{P}>0.05)$. However, the rate of advanced GC (AGC) in the ERH-UE group was significantly higher than that in the ERH-OE group (73.7\% vs. $43.1 \% ; \mathrm{P}<0.01)$. In terms of TNM stage, the proportion of high stages in the ERH-UE group was significantly higher than that in the ERH-OE group (stage I, II, and IIIIV; $28.9 \%$ vs. $64.4 \%, 42.1 \%$ vs. $14.6 \%$ and $28.9 \%$ vs. $21 \%$, respectively, $\mathrm{P}<0.01)$. In addition, the cancer recurrence rate was higher in the ERH-UE group than in the ERHOE group (31.6\% vs. 16.7\%, $\mathrm{P}=0.04$ ) (Table 1).

Based on analysis of the cumulative survival rate between the two groups, patients in the ERH-OE group (85.8 months, 95\% CI: 82.7-88.9 months) had longer cumulative survival times than did those in the ERH-UE group (67.7 months, 95\% CI: 58.7-76.7 months), and the difference was significant (log-rank test, $\mathrm{P}=0.04$ ) (Figure 2).

\section{ERH-OE suppressed GC cell migration and invasion but had no effect on cell proliferation in vitro}

The effect of ERH-OE on the proliferation, migration 
Table 1 Comparison of the clinicopathological features of the ERH under expression and overexpression groups according to IHC of tissues from 319 GC patients

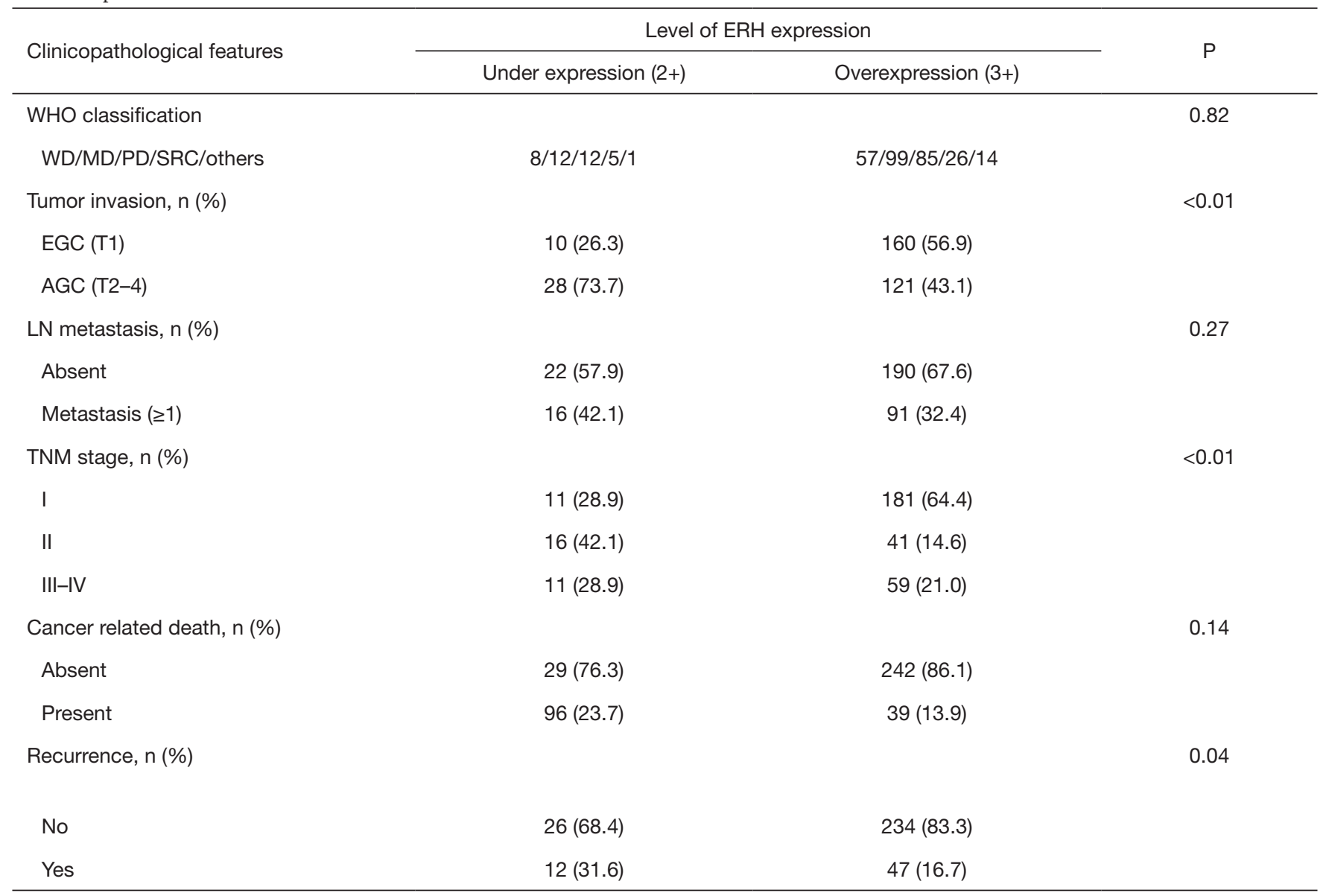

$\mathrm{ERH}$, enhancer of rudimentary homolog; IHC, immunohistochemistry; GC, gastric cancer; WD, well differentiated; MD, moderately differentiated; PD, poorly differentiated; SRC, signet ring cell carcinoma; EGC, early gastric cancer; AGC, advanced gastric cancer; LN, lymph node.

and invasion of cancer cells was evaluated in SNU601 and MKN74 cells. Before the assay, ERH-OE in the cells from two SNU601 cell groups (oeERH-1 \& 2) and MKN74 cell groups (oeERH-1 \& 2) was confirmed by immunoblotting with an antibody against ERH (Figure 3A). We did not find differences in the proliferation rates between the ERH-overexpressing SNU601 and MKN74 cells and the respective control cells (Figure 3B). However, we found that the migration and invasion rates of both groups of ERH-overexpressing cell lines were lower than those of the control cells (Figure 3C,D).

\section{Depletion of ERH expression triggered GC cell migration and invasion but had no effect on proliferation in vitro}

The function of ERH in the proliferation, migration and invasion of GC cells was evaluated using ERH-specific siRNAs (siERH-1 \& 2) to inhibit ERH expression in SNU601 and MKN74 cells, respectively. The specificity of the 2 different ERH siRNAs was first confirmed (Figure $4 A$ ). The proliferation rates of the ERH-depleted SNU601 and MKN74 cells were not significantly different from those of the control cells (Figure 4B), though the migration rate of the ERH-depleted SNU601 and MKN74 cells was increased compared to that of the respective control cells (Figure 4C). ERH depletion had similar effects on cell invasion rates, whereby the invasion rates for the ERH-depleted SNU601 and MKN74 cells were significantly increased compared to those of control cells (Figure 4D). These results suggest that ERH expression reduces the invasion of GC cells. 


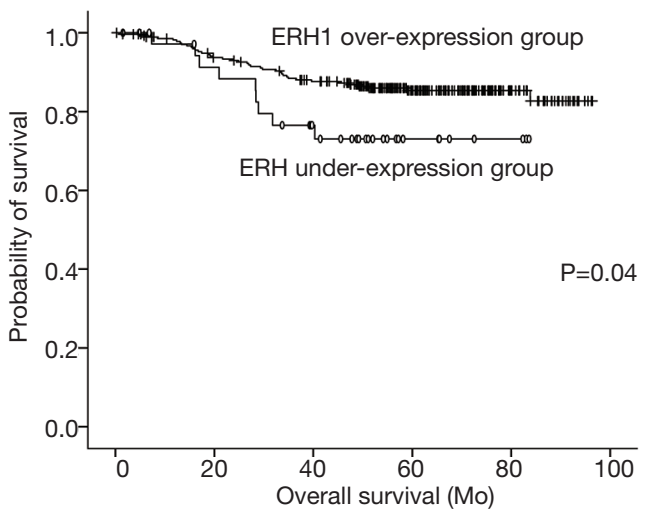

Figure 2 Underexpressed ERH is associated with a shorter survival time. The ERH-OE group showed a longer cumulative survival time compared with the ERH-UE group according to the results of Kaplan-Meier survival analysis. ERH, enhancer of rudimentary homolog; ERH-OE, ERH overexpression; ERH-UE, ERH underexpression.

\section{Discussion}

In our previous proteomics study, ERH was found to be upregulated in GC tissues compared to healthy tissues. According to IHC analysis, patients whose tumors overexpressed ERH had lower T stage and lower TNM stage classifications, lower cancer recurrence rates and longer survival times than did patients whose tumors expressed ERH. In vitro, forced expression of ERH caused a significant decrease in GC cell migration and invasion, whereas ERH depletion induced a significant increase in GC cell migration.

The standard adjuvant chemotherapy for GC is S-1 and Xeloda with oxaliplatin, with the only positive result in the ACTS-GC and CLASSIC trials of GC chemotherapy $(14,15)$. The first targeted agent against GC was trastuzumab, a monoclonal antibody that targets HER2 to induce antibody-dependent cellular cytotoxicity (5). Trastuzumab conferred a survival benefit in patients with HER2-positive breast cancer, and this benefit was also found in patients with GC in the ToGA trial (16). However, GC analysis revealed HER2 overexpression in $7-34 \%$ of the tumors. Additionally, the survival gain was approximately 2.7 months compared with 11.3 months for chemotherapy alone and 13.8 months for chemotherapy with trastuzumab. Recently, pembrolizumab, a humanized antibody that targets the programmed cell death protein 1 receptor of lymphocytes (PD-L1), has been actively studied for targeted therapy (17). Pembrolizumab was approved for medical use in the USA in 2014, and it received FDA approval in 2017 for use in any unresectable or metastatic solid tumor with certain genetic anomalies (mismatch repair deficiency or microsatellite instability). Currently, pembrolizumab is used as the first-line treatment for inoperable or metastatic melanoma and metastatic nonsmall cell lung cancer. It is also used as a second-line treatment for head and neck squamous cell carcinoma, after platinum-based chemotherapy, for the treatment of adult and pediatric patients with classic refractory Hodgkin's lymphoma and for locally recurrent advanced or metastatic esophageal squamous cell carcinoma (18-21). A clinical trial is underway to identify chemotherapy agents against PDL1 by comparing the following treatments: pembrolizumab alone $v s$. paclitaxel with pembrolizumab vs. chemotherapy alone $(6,22)$. Although the results will be available in several years, we currently need improved targeted agents.

The enhancer of the rudimentary gene in Drosophila melanogaster encodes an enhancer of the rudimentary protein, a small protein of 104 amino acids $(23,24)$. ERH is a highly conserved protein found in plants, animals, and protists. ERH is encoded by a constitutive housekeeping gene, is required for the maintenance of basic cellular functions and is expressed in all cells of an organism under normal and pathophysiological conditions. ERH might play a role in the regulation of pyrimidine metabolism. Flies with hypomorphic mutations in ERH were reported to be viable, but homozygous deletion of this gene severely reduced viability (25). ERH may be involved in various cellular functions. Indeed, ERH might play a role in transcriptional elongation and interact with the RNA Pol II C-terminal domain phosphatase FCP1 and the transcription factor SPT5, which regulates RNA Pol II elongation $(10,26)$. In particular, ERH plays an essential role in the progression of mitosis by promoting mitotic chromosome alignment (9). Depletion of ERH compromises kinetochore-microtubule attachment, a process that is essential for chromosome alignment at the metaphase plate (9). RNAi-mediated ERH knockdown leads to G2/M arrest and chromosome congression defects (27). Moreover, ERH binds to the Sm complex and is required for the mRNA splicing of the mitotic motor protein CENP-E. ERH affects carcinogenesis in many ways. This protein is reported to be an important survival factor in pancreatic, breast, and ovarian cell lines (28). Additionally, functional evidence supporting a role for ERH in mRNA splicing was obtained 
A

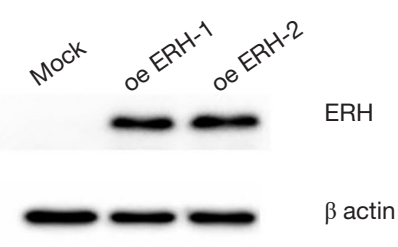

SNU-601

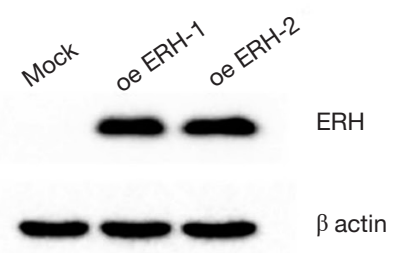

MKN-74

C
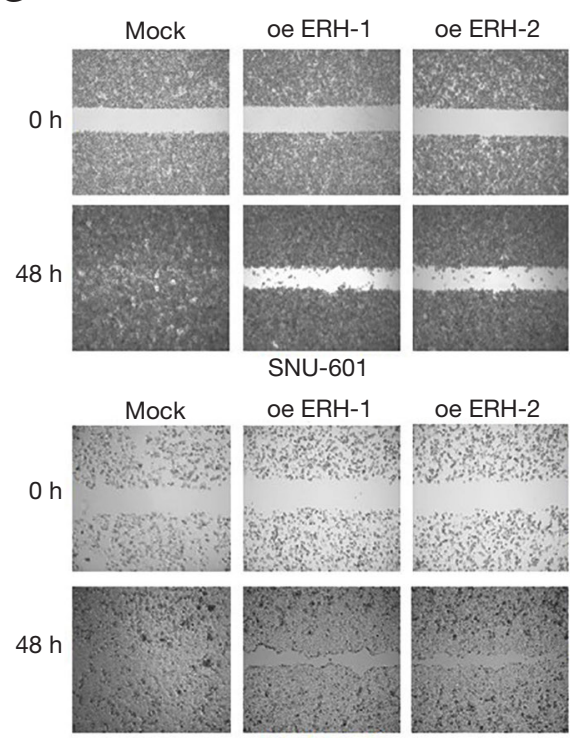

MKN-74
B
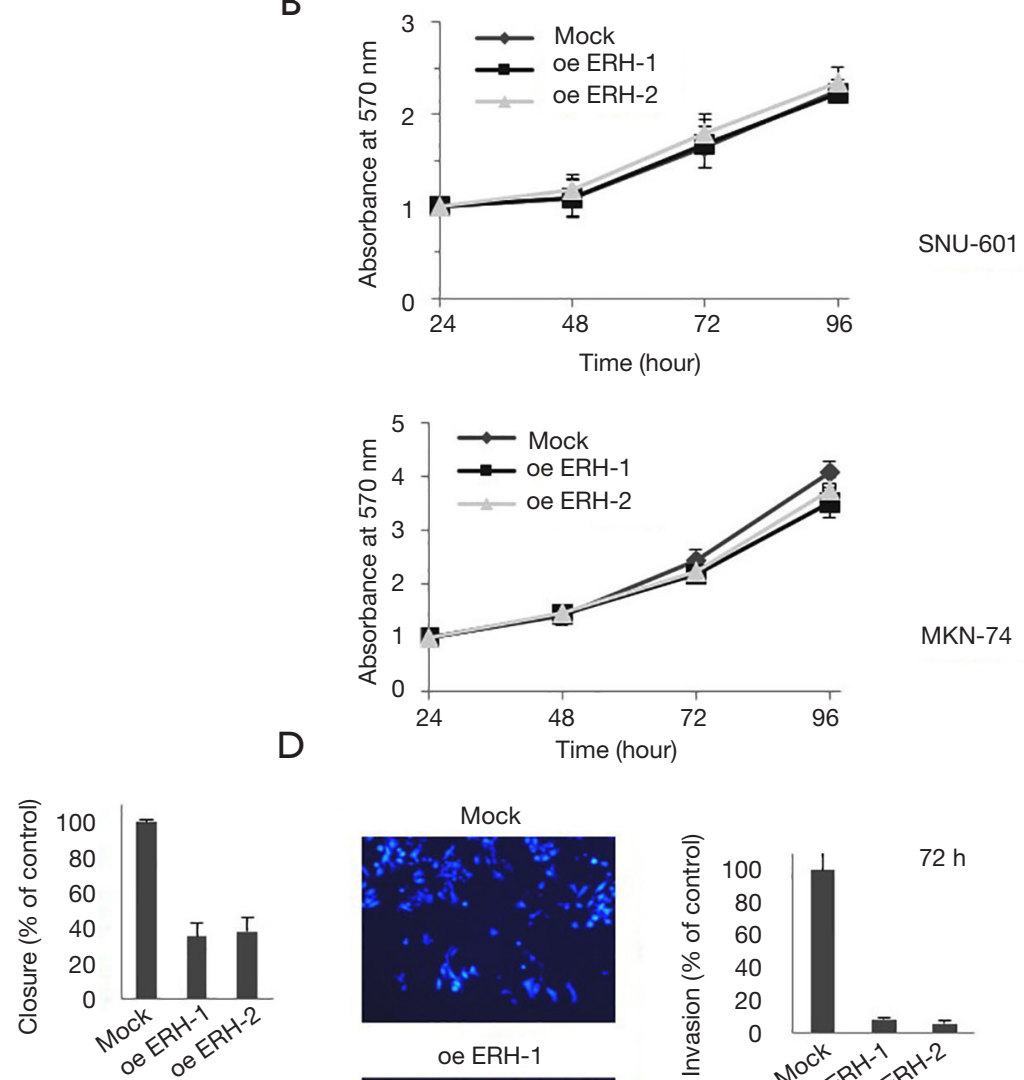

oe ERH-1

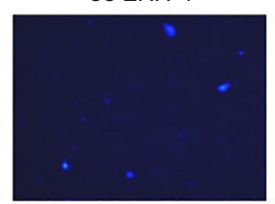

oe ERH-2
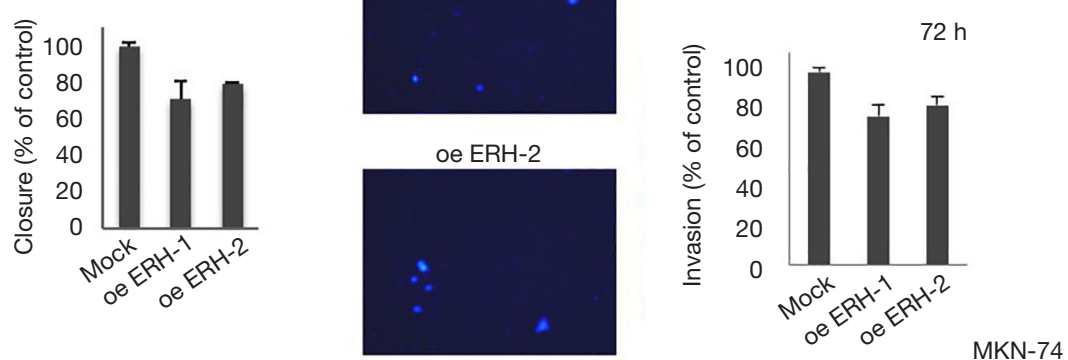

Figure 3 ERH-OE in 2 SNU601 cell groups (oeERH-1 \& 2) and 2 MKN74 cell groups (oeERH-1 \& 2) was confirmed using Western blot analysis (A); cell proliferation was determined by a MTT assay (B); wound-closure rates were measured (C); invasive ability was evaluated using a Transwell assay (D) with overexpressed ERH in SNU601 and MKN74 cells and their respective controls. Data are presented as the mean \pm SD for triplicate independent experiments, and the error bars indicate SD. ERH, enhancer of rudimentary homolog; ERH-OE, ERH overexpression; MTT, 3-(4,5-dimethylthiazol-2-yl)-2,5-diphenyltetrazolium bromide.

from an analysis of the mRNA of centromere-associated protein E. ERH is also reported to interact with the tumor suppressor protein H19 against a tumor suppressor (HOTS) (29).

Weng et al. found that ERH depletion led to a greater suppression of viability in KRAS mutant cell lines than in
WT KRAS cell lines (30). ERH mRNA expression has been associated with short-term survival among colorectal cancer patients with KRAS mutations, with no effect in patients with WT KRAS. Similarly, high ERH expression decreased the survival of patients with lung tumors carrying $K R A S$ mutations, but no such influence was found for patients 
A

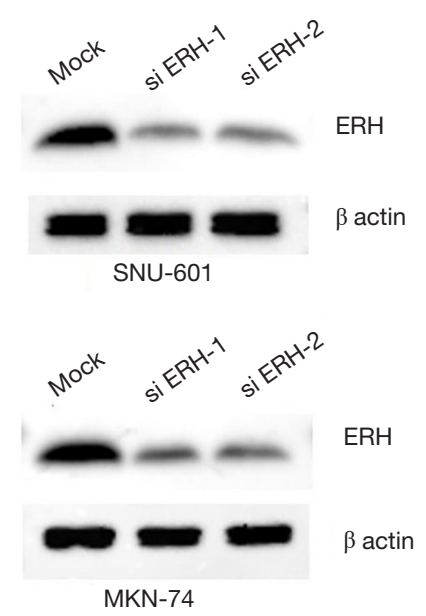

C
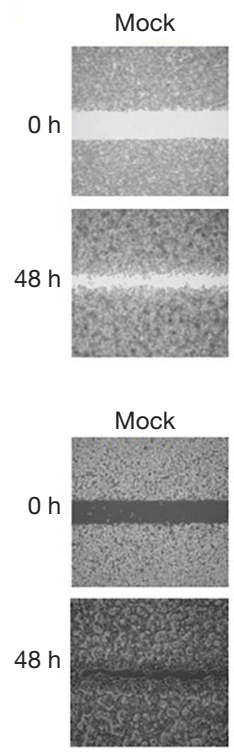
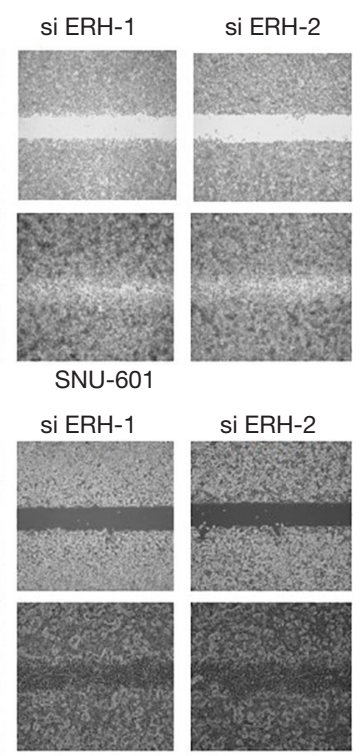

MKN-74

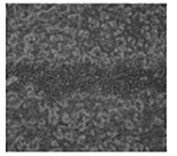

B

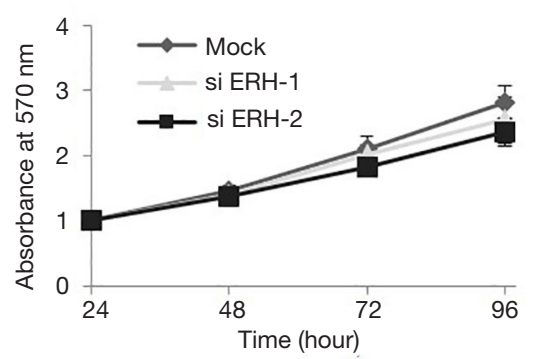

SNU-601

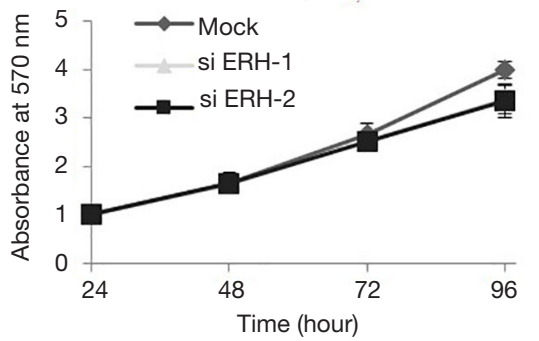

MKN-74

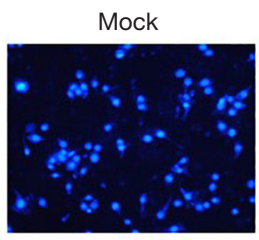

si $\mathrm{ERH}-1$
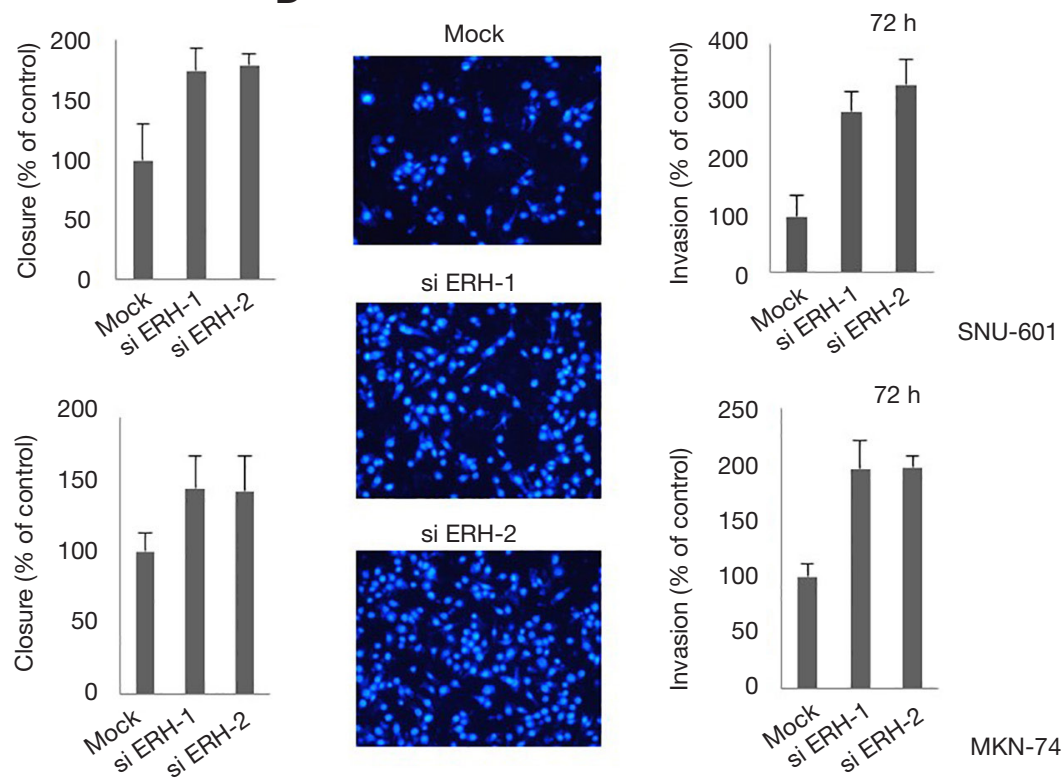

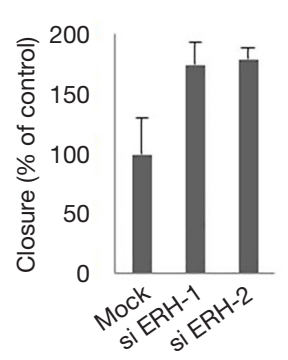

Figure 4 Depletion of ERH expression in 2 SNU601 cell groups (siERH-1 \& 2) and 2 MKN74 cell groups (siERH-1 \& 2) was confirmed using Western blot analysis (A); MTT assays were used to evaluate proliferation in SNU601 and MKN74 cell lines (B); cell migration was evaluated using a wound-healing assay (C); invasive ability was evaluated using a Transwell assay (D). Data are presented as the mean \pm SD for triplicate independent experiments, and the error bars indicate SD. ERH, enhancer of rudimentary homolog; MTT, 3-(4,5-dimethylthiazol-2-yl)-2,5-diphenyltetrazolium bromide.

with WT KRAS or an EGFR mutation. Furthermore, Weng et al. reported that ERH regulates the DNA damage response in hepatocellular carcinoma and that increased levels of ERH were present in tumor tissues compared with nontumor tissues (31).

The $E R H$ gene also regulates migration and invasion in urothelial carcinoma of the bladder (32). Pang et al. suggested that knocking out ERH inhibits migration and invasion through MYC in bladder urothelial carcinoma T24 cells. In addition, a recent study of ovarian cancer revealed the potential of ERH as a marker for a poor prognosis (33). Inhibition of ERH expression slows proliferation, promotes apoptosis and inhibits metastasis and invasion by regulating epithelial-mesenchymal transition 
in ovarian cancer cells. These studies showed that patients with low ERH expression had a good prognosis, but we found that those with high ERH expression had better survival and lower levels of migration and invasion than did those with low ERH expression, which could be explained by stomach cancer- or tissue-specific phenomena. In fact, there are many cases in which one transcription factor plays opposite roles. Another theory is related to our finding from the proteomics study of 9.1-fold greater ERH expression in GC tumor tissues than in normal gastric tissues. Additionally, the percentage of cancers overexpressing ERH that had a TMA score of 3 was $88 \%$, and only $11 \%$ of the cancers had a TMA score of 2. All of the tumors with low ERH expression had a score of 2 . Therefore, in general, the proportion of tumors expressing ERH is not low, even in the group with ERH-UE.

One of the limitations of the present study was that the group with a score of 2 (ERH-UE, 11\%) was too small to compare with the group with a score of 3 (ERH-OE, $88 \%)$; in these two groups, the sample size representing advanced-stage cancer, which was used in IHC analysis, was small compared to the sample size representing early-stage cancer. Nevertheless, to our knowledge, this is the largest proteomics and immunohistochemical study evaluating ERH expression in human GC tissues. Regardless, further studies on the mechanism of ERH related to prognosis through a stable knockout cell line and in vivo experiments are needed. In conclusion, patients with ERH-OE in their GC tissues have a better prognosis than do those with ERH-UE. The ERH-OE group had better survival than the ERH-UE group. Therefore, ERH may be a potential biomarker for good prognosis in patients with GC, though further studies are needed to confirm these results.

\section{Acknowledgments}

Funding: This work was supported by biomedical research institute fund (GNUHBRIF-2020-0006) from the Gyeongsang National University Hospital.

\section{Footnote}

Reporting Checklist: The authors have completed the REMARK reporting checklist. Available at http://dx.doi. org/10.21037/tcr-20-1498

Data Sharing Statement: Available at http://dx.doi. org/10.21037/tcr-20-1498
Peer Review File: Available at http://dx.doi.org/10.21037/tcr20-1498

Conflicts of Interest: All authors have completed the ICMJE uniform disclosure form (available at http://dx.doi. org/10.21037/tcr-20-1498). The authors have no conflicts of interest to declare.

Ethical Statement: The authors are accountable for all aspects of the work in ensuring that questions related to the accuracy or integrity of any part of the work are appropriately investigated and resolved. The study was conducted in accordance with the Declaration of Helsinki (as revised in 2013). The study was approved by the Institutional Review Board of Gyeongsang National University Hospital (GNUHIRB 2009-54) and informed consent was taken from all the patients.

Open Access Statement: This is an Open Access article distributed in accordance with the Creative Commons Attribution-NonCommercial-NoDerivs 4.0 International License (CC BY-NC-ND 4.0), which permits the noncommercial replication and distribution of the article with the strict proviso that no changes or edits are made and the original work is properly cited (including links to both the formal publication through the relevant DOI and the license). See: https://creativecommons.org/licenses/by-nc-nd/4.0/.

\section{References}

1. Ferro A, Peleteiro B, Malvezzi M, et al. Worldwide trends in gastric cancer mortality (1980-2011), with predictions to 2015 , and incidence by subtype. Eur J Cancer 2014;50:1330-44.

2. Sasako M, Sakuramoto S, Katai H, et al. Five-year outcomes of a randomized phase III trial comparing adjuvant chemotherapy with S-1 versus surgery alone in stage II or III gastric cancer. J Clin Oncol 2011;29:4387-93.

3. Noh SH, Park SR, Yang HK, et al. Adjuvant capecitabine plus oxaliplatin for gastric cancer after D2 gastrectomy (CLASSIC): 5-year follow-up of an open-label, randomised phase 3 trial. Lancet Oncol 2014;15:1389-96.

4. Smyth EC, Cunningham D. Targeted therapy for gastric cancer. Curr Treat Options Oncol 2012;13:377-89.

5. Bang YJ, Van Cutsem E, Feyereislova A, et al. Trastuzumab in combination with chemotherapy versus chemotherapy alone for treatment of HER2-positive advanced gastric or gastro-oesophageal junction cancer 
(ToGA): a phase 3, open-label, randomised controlled trial. Lancet 2010;376:687-97.

6. Brar G, Shah MA. The role of pembrolizumab in the treatment of PD-L1 expressing gastric and gastroesophageal junction adenocarcinoma. Therap Adv Gastroenterol 2019;12:1756284819869767.

7. Lim BH, Cho BI, Kim YN, et al. Overexpression of nicotinamide $\mathrm{N}$-methyltransferase in gastric cancer tissues and its potential post-translational modification. Exp Mol Med 2006;38:455-65.

8. Smyk A, Szuminska M, Uniewicz KA, et al. Human enhancer of rudimentary is a molecular partner of PDIP46/SKAR, a protein interacting with DNA polymerase delta and S6K1 and regulating cell growth. FEBS J 2006;273:4728-41.

9. Fujimura A, Kishimoto H, Yanagisawa J, et al. Enhancer of rudimentary homolog (ERH) plays an essential role in the progression of mitosis by promoting mitotic chromosome alignment. Biochem Biophys Res Commun 2012;423:588-92.

10. Kwak YT, Guo J, Prajapati S, et al. Methylation of SPT5 regulates its interaction with RNA polymerase II and transcriptional elongation properties. Mol Cell 2003;11:1055-66.

11. Lukasik A, Uniewicz KA, Kulis M, et al. Ciz1, a p21 cip1/ Waf1-interacting zinc finger protein and DNA replication factor, is a novel molecular partner for human enhancer of rudimentary homolog. FEBS J 2008;275:332-40.

12. Zafrakas M, Losen I, Knuchel R, et al. Enhancer of the rudimentary gene homologue (ERH) expression pattern in sporadic human breast cancer and normal breast tissue. BMC Cancer 2008;8:145.

13. Kimura M, Tsuda H, Morita D, et al. A proposal for diagnostically meaningful criteria to classify increased epidermal growth factor receptor and c-erbB-2 gene copy numbers in gastric carcinoma, based on correlation of fluorescence in situ hybridization and immunohistochemical measurements. Virchows Arch 2004;445:255-62.

14. Sakuramoto S, Sasako M, Yamaguchi T, et al. Adjuvant chemotherapy for gastric cancer with S-1, an oral fluoropyrimidine. N Engl J Med 2007;357:1810-20.

15. Bang YJ, Kim YW, Yang HK, et al. Adjuvant capecitabine and oxaliplatin for gastric cancer after D2 gastrectomy (CLASSIC): a phase 3 open-label, randomised controlled trial. Lancet 2012;379:315-21.

16. Gown AM. Current issues in ER and HER2 testing by IHC in breast cancer. Mod Pathol 2008;21 Suppl 2:S8-15.
17. Robert C, Ribas A, Wolchok JD, et al. Anti-programmeddeath-receptor-1 treatment with pembrolizumab in ipilimumab-refractory advanced melanoma: a randomised dose-comparison cohort of a phase 1 trial. Lancet 2014;384:1109-17.

18. Fuereder T. Immunotherapy for head and neck squamous cell carcinoma. Memo 2016;9:66-9.

19. Redman JM, Gibney GT, Atkins MB. Advances in immunotherapy for melanoma. BMC Med 2016;14:20.

20. Syn NL, Teng MWL, Mok TSK, et al. De-novo and acquired resistance to immune checkpoint targeting. Lancet Oncol 2017;18:e731-41.

21. Vachhani P, Chen H. Spotlight on pembrolizumab in nonsmall cell lung cancer: the evidence to date. Onco Targets Ther 2016;9:5855-66.

22. 2019 ASCO: KEYNOTE-062: Pembrolizumab with or without chemotherapy vs chemotherapy in advanced gastric or GEJ adenocarcinoma. 2019. Available online: https://www.ascopost.com/News/60099

23. Gelsthorpe M, Pulumati M, McCallum C, et al. The putative cell cycle gene, enhancer of rudimentary, encodes a highly conserved protein found in plants and animals. Gene 1997;186:189-95.

24. Wojcik E, Murphy AM, Fares H, et al. Enhancer of rudimentaryp1, e(r)p1, a highly conserved enhancer of the rudimentary gene. Genetics 1994;138:1163-70.

25. Roykhman M, Ibach S, Harding D, et al. The generation and analysis of deficiencies within a small genomic region on the $\mathrm{X}$ chromosome of Drosophila melanogaster containing two genes, enhancer of rudimentary and CG15352. Fly (Austin) 2007;1:245-50.

26. Amente S, Napolitano G, Licciardo P, et al. Identification of proteins interacting with the RNAPII FCP1 phosphatase: FCP1 forms a complex with arginine methyltransferase PRMT5 and it is a substrate for PRMT5-mediated methylation. FEBS Lett 2005;579:683-9.

27. Kops GJ, Saurin AT, Meraldi P. Finding the middle ground: how kinetochores power chromosome congression. Cell Mol Life Sci 2010;67:2145-61.

28. Luo J, Emanuele MJ, Li D, et al. A genome-wide RNAi screen identifies multiple synthetic lethal interactions with the Ras oncogene. Cell 2009;137:835-48.

29. Onyango P, Feinberg AP. A nucleolar protein, H19 opposite tumor suppressor (HOTS), is a tumor growth inhibitor encoded by a human imprinted H19 antisense transcript. Proc Natl Acad Sci U S A 2011;108:16759-64.

30. Weng MT, Lee JH, Wei SC, et al. Evolutionarily 
conserved protein ERH controls CENP-E mRNA splicing and is required for the survival of KRAS mutant cancer cells. Proc Natl Acad Sci U S A 2012;109:E3659-67.

31. Weng MT, Tung TH, Lee JH, et al. Enhancer of rudimentary homolog regulates DNA damage response in hepatocellular carcinoma. Sci Rep 2015;5:9357.

32. Pang $\mathrm{K}$, Zhang $\mathrm{Z}$, Hao L, et al. The ERH gene regulates migration and invasion in 5637 and T24 bladder cancer cells. BMC Cancer 2019;19:225.

33. Zhang D, Chu YJ, Song KJ, et al. Knockdown of enhancer of rudimentary homolog inhibits proliferation and metastasis in ovarian cancer by regulating epithelialmesenchymal transition. Biomed Pharmacother 2020;125:109974.
Cite this article as: Park JH, Park M, Park SY, Lee YJ, Hong SC, Jung EJ, Ju Y'T, Jeong CY, Kim JY, Ko GH, Hah YS, Jeong SH. ERH overexpression is associated with decreased cell migration and invasion and a good prognosis in gastric cancer. Transl Cancer Res 2020;9(9):5281-5291. doi: 10.21037/tcr-20-1498 